\title{
The effect of a cyclonic eddy on the distribution of lithogenic particles in the southern East China Sea
}

\author{
by Shih-Chieh Hsu' ${ }^{1}$, Fei-Jan Lin ${ }^{1}$, Woei-Lih Jeng ${ }^{1,2}$ and Tswen Yung Tang1
}

\begin{abstract}
Off northeastern Taiwan, the collision between the Kuroshio Current (KC) and the East China Sea (ECS) shelf forms a branch current (Kuroshio Branch Current) on the shelf, and the counterclockwise deflection of the subsurface Kuroshio water annually generates a cyclonic eddy, about $70 \mathrm{~km}$ in diameter, over the shelf-slope in summer. In this study, the total suspended matter collected from varying water depths over the eddy during August 1994 has been analyzed for Al, which is used as an indicator element to trace lithogenic particle transport. Simultaneously, the measurements of current field, using the Shipboard Acoustic Doppler Current Profiler, and hydrography have also been conducted on the same cruise during the seawater sampling. These offer an opportunity for direct examination of the relationships between circulation patterns and distributions of lithogenic particles to further establish a transport model for lithogenic particles. However, we must emphasize that this is a representative case for the export of terrigenous suspensions delivered from rivers, although the observation was made only in summer.

The spatial distribution of particulate $\mathrm{Al}$ (PAl) in the upper water displays an " $\Omega$ " shape with high concentrations of PAl close to the Taiwan coast and around the eddy center. It suggests that Taiwan-derived riverborne particulates are the main source for the lithogenic particles in the upper water of the study area. Moreover, the PAl in the upper water is essentially constrained by the cyclonic eddy, and the entrainment and subsequent accumulation of lithogenic particles occur at the eddy center. The $6 \mu \mathrm{g} / \mathrm{l}$ contour of PAl in the upper water almost matches the western boundary of the main stream and branch of the KC across the ECS shelf-slope, and two concentration provinces of PAl can be identified from this contour: one to the west is larger and variable and the other to the east is smaller and uniform. This indicates that the main stream and branch of the $\mathrm{KC}$ may confine terrigenous particles to the inshore area where mixing of the lithogenic particle-rich coastal water and the clearer Kuroshio water occurs and may act as a barrier to the offshore transport of terrigenous particles to regions farther away from the coast, toward the north and east.

In this study, a conceptual model for the transport of lithogenic particles in the water of the southern ECS is proposed according to the spatial distributions of PAl. This model suggests that the cyclonic eddy at the turning site of the $\mathrm{KC}$ may be the important conduit for the indirect transport of terrigenous particles from the ECS shelf and slope to the southern Okinawa Trough or the Pacific Ocean. This is also a valuable example of the role of the eddy system in regulating the distribution and transport of terrigenous particulates.
\end{abstract}

1. Institute of Oceanography, National Taiwan University, Taipei, Taiwan, Republic of China.

2. Author to whom correspondence should be sent. 


\section{Introduction}

Recently, oceanographers have gradually paid more attention to the eddy systems because of their effect on the deposition of sediments, primary production, and exchange and interaction of water masses and nutrients in oceans (The Ring Group, 1981; Simpson et al., 1984; Nelson et al., 1985; Wiebe and McDougall, 1986; Wolanski and Hamner, 1988; Hayward and Mantyla, 1990; Falkowski et al., 1991; Smith et al., 1996). Usually, cyclonic eddies induce upwelling, whereas the anticyclonic eddies induce downwelling. In the cyclonic eddies, primary production is dramatically enhanced by the ascended nutrientrich water from upwelling. This has been confirmed by determinations of chlorophyll $a$ and primary productivity (The Ring Group, 1981; Falkowski et al., 1991; Aristegui et al., 1997). Eddy systems may also influence the transport of suspended particulates and then the deposition of sediments (Haidvogel et al., 1983; Bishop and Joyce, 1986). For example, Hu (1984) found that the distribution of fine-grained mud patches on the continental shelf of the East China Sea (ECS) and the Yellow Sea was closely related to the cyclonic gyre systems in this region. It reflects that the cyclonic rotation of eddies requiring horizontal inflow may draw the fine lithogenic particles and accumulate them in eddy centers to subsequently deposit beneath the eddies ( $\mathrm{Qu}$ and Hu, 1993). The accumulation of suspended particulate matter (SPM) in eddy centers was observed at warm-core rings in the Gulf Stream (Nelson et al., 1985; Bishop and Joyce, 1986); however, the SPM studied by them was dominated by biogenic matter. Thus, the accumulation of material from the in situ production in eddy centers and that through the entrainments from surrounding water cannot be distinguished (Bishop and Joyce, 1986). In contrast to biogenic matter, lithogenic particles are a better tracer to distinguish these two kinds of accumulation since they come predominantly from terrigenous sources and have little in situ production (authigenic) in coastal oceans.

In such an eddy with high productivity, high biological feeding activities and high production of fecal pellets excreted by marine organisms may further change the distribution of suspended particles and nutrients (McCarthy and Nevins, 1986; Bishop et al., 1986) as well as of dissolved metals in ambient water, especially in the upper water column. Biogenic material possibly promotes the removal of lithogenic particles and trace metals via the "great particle conspiracy" or "piggy-back" mechanism through aggregation of biogenous and terrigenous debris as well as authigenic particulates from overlying water (Turekian, 1977; Lal, 1980; Honjo et al., 1982; Deuser et al., 1983). Thus, a variety of processes, such as physical, chemical and biological processes, could affect the interaction and distribution of terrigenous particles and dissolved metals in the water column once they are introduced to the sea.

In Taiwan, there is a fast denudation rate $(\mathrm{Li}, 1976)$, and the steep mountainous terrain and heavy rainfall produce a high sediment yield of up to $14200 \mathrm{t} / \mathrm{km}^{2} / \mathrm{yr}$, about two orders of magnitude more than the world mean estimated by Milliman (1991). According to the long-term measurements made by the Water Resources Bureau of Taiwan (1997), the mean annual sediment discharges from Taiwan's rivers are about $263 \mathrm{Mt}$; near the study area, the 


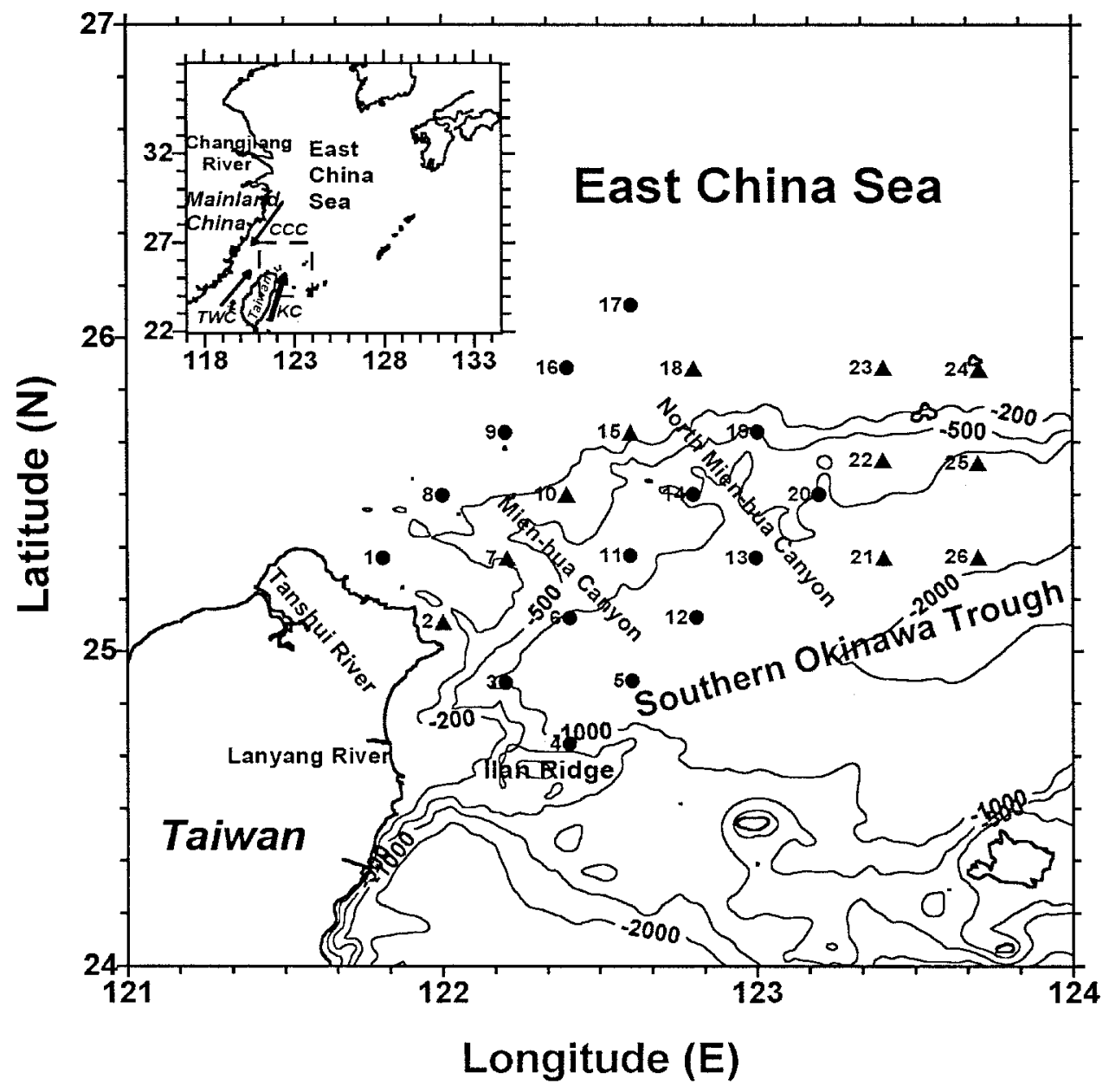

Figure 1. Sampling locations in the southern East China Sea. The stations for total suspended matter are denoted by solid circles; the hydrographic stations are denoted by solid circles and triangles. The regional bathymetry is also drawn. In northern and eastern Taiwan, two representative large rivers, i.e., Tanshui and Lanyang Rivers, also are presented. Inset shows the three major currents (Kuroshio Current (KC), Changjiang Coastal Current (CCC) and Taiwan Warm Current (TWC) in the region.

Lanyang and Tanshui Rivers (see Fig. 1) have mean annual sediment discharges of around 8 and $11 \mathrm{Mt}$, respectively. The ECS, with its wide continental shelf, receives enormous amounts of sediments from both the Changjiang and Hunghe Rivers, which produce annual sediment discharges of about 478 and $1080 \mathrm{Mt}$, respectively (Milliman and Meade, 1983). Milliman et al. (1985) suggest that $60 \%$ of the sediment load exported from the Changjiang is carried southward by coastal and tidal currents. Additionally, because Taiwan and Mainland China are industrialized and gradually industrializing, respectively, many 


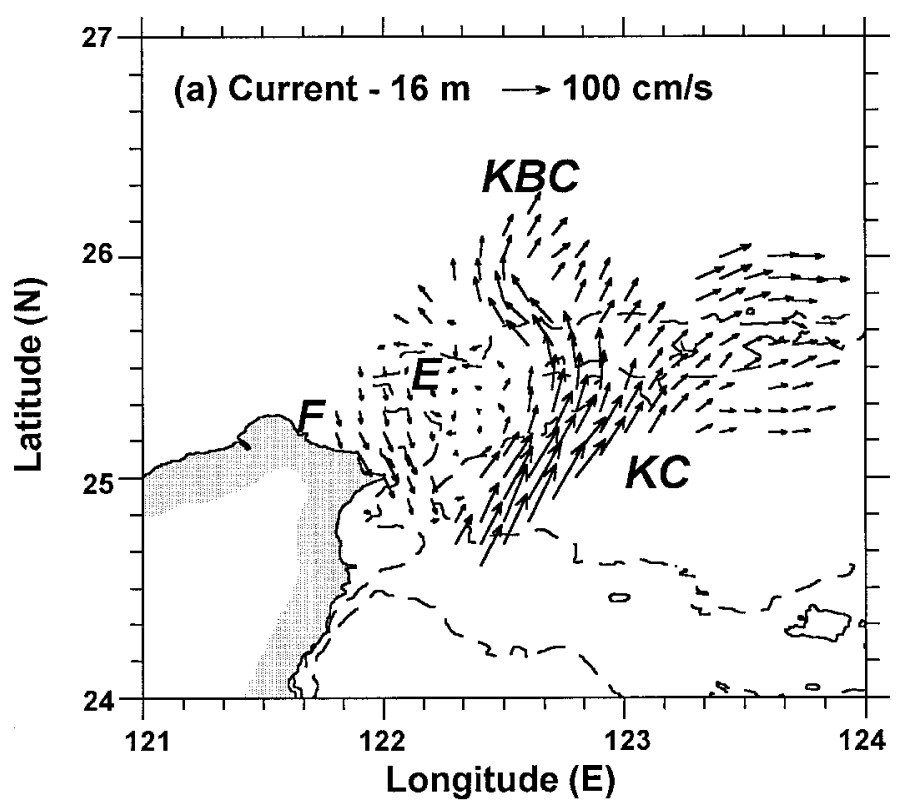

Figure 2. Horizontal patterns of (a) current field (at $16 \mathrm{~m}$ ), (b) temperature field (at $8 \mathrm{~m}$ ) and (c) salinity field (at $8 \mathrm{~m}$ ), measured on the same cruise during total suspended matter sampling. The Kuroshio Current is designated as KC; the Kuroshio Branch Current, KBC; the cyclonic eddy, E; and the filament, $\mathrm{F}$.

pollutants accompanying transported sediment are introduced into the ECS and then transported, possibly to the Okinawa Trough (OT). If so, the area off northeast Taiwan would be an important conduit for the seaward transport of river and shelf sediments. However, this area is in a complicated and dynamic environment because of its geological, physical, chemical and biological conditions. To evaluate the output fluxes of materials from the southern ECS to the OT is one of the objectives of the Kuroshio-East China Sea Shelf Exchange Processes (KEEP) project underway in Taiwan.

In coastal oceans, cyclonic and anticyclonic eddies are commonly generated by the interaction between the main currents and topography as well as by wind stress (Robinson, 1983). Due to the collision between the Kuroshio Current (KC) and the ECS shelf, a cyclonic eddy generates annually over the shelf-slope off northeastern Taiwan in summer (Tang et al., 1998). Because suspended particulates, current field and hydrography have been investigated together in this study, therefore, it may give us an opportunity to examine the role of the eddy systems in regulating the distribution and transport of lithogenic particles. This research demonstrates a close relation between distribution and transport of lithogenic particles and circulation patterns.

\section{Background to circulation patterns in the study area}

The ECS shelf is under the influence of interactions between three major currents: the Changjiang Coastal Current (CCC), the Taiwan Warm Current (TWC) and the KC (Fig. 1). 

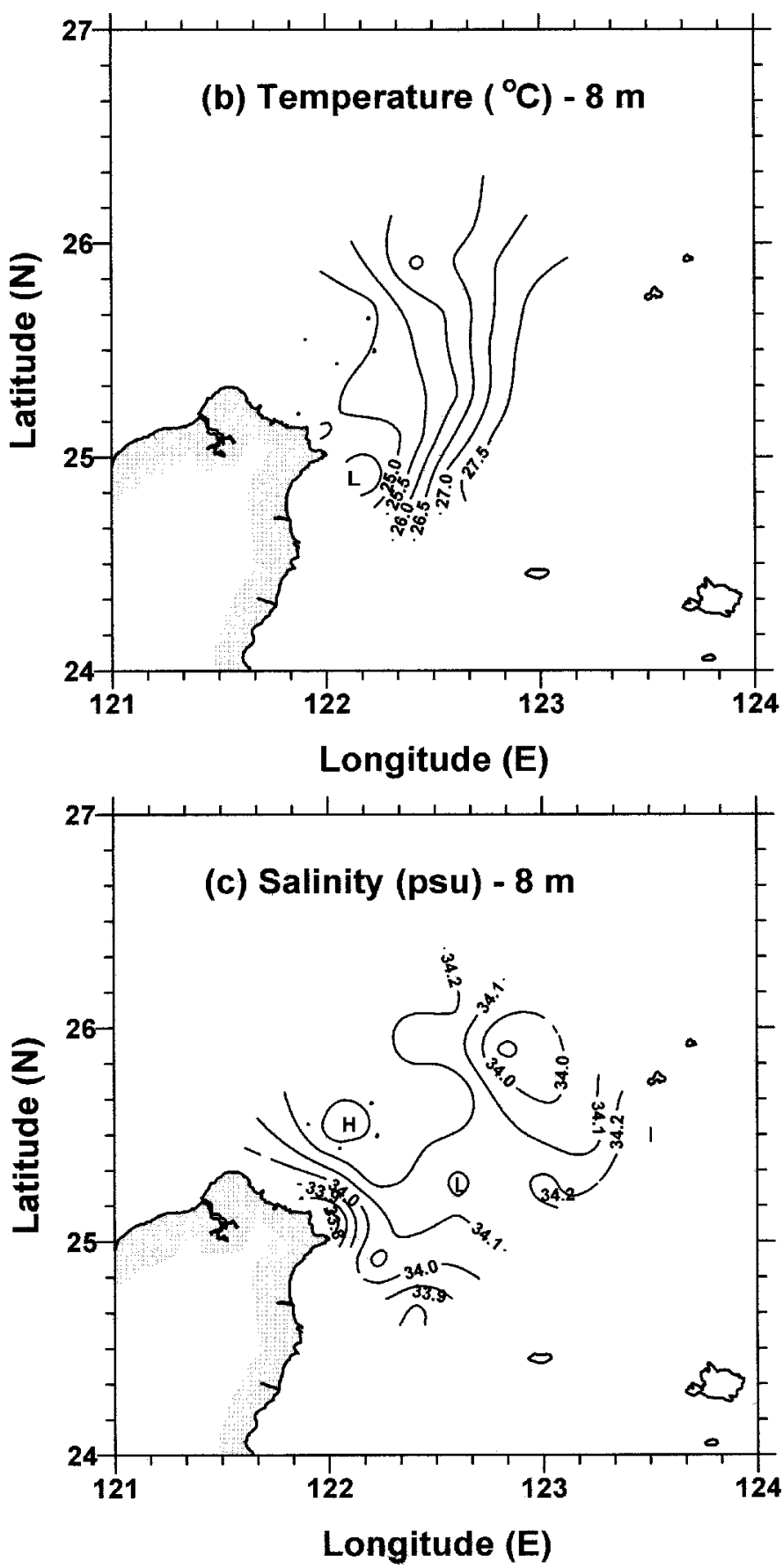

Figure 2. (Continued) 


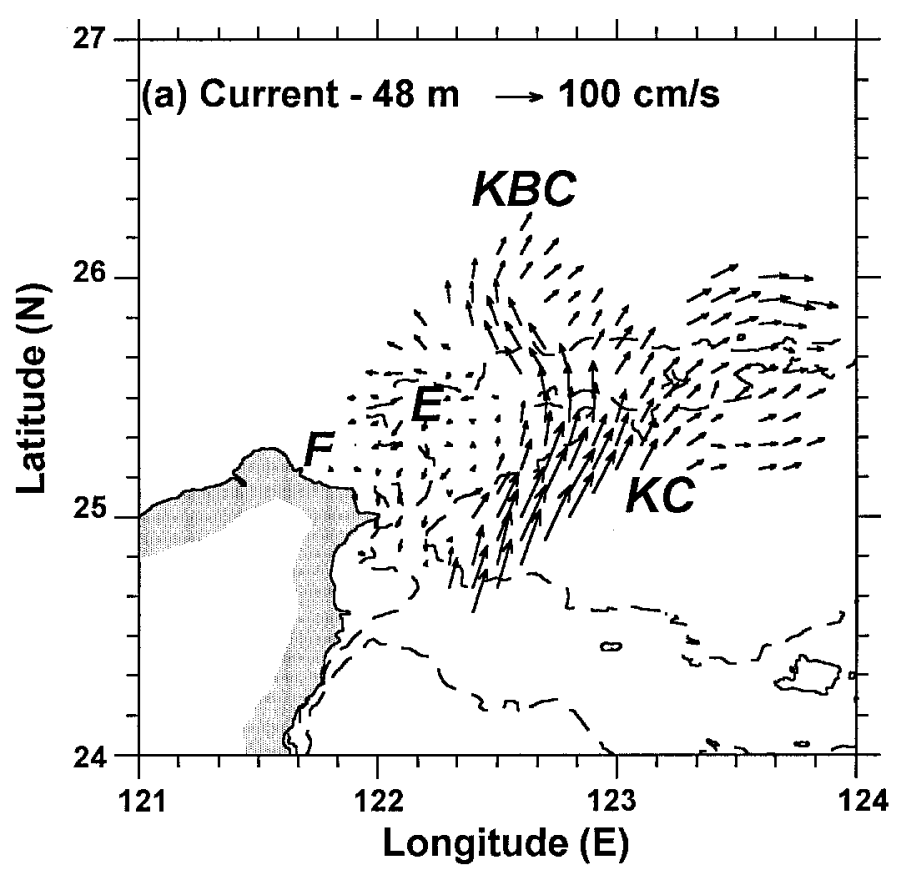

Figure 3. As in Figure 2, but for $48 \mathrm{~m}$ depth.

The KC flows northward along the east coast of Taiwan. When approaching northeastern Taiwan offshore, it collides with the shoaling east-west shelf of the southern ECS somewhere near the North Mien-hua Canyon; consequently, a variety of physical phenomena occur (Chern et al., 1990; Liu et al., 1992; Hsueh et al., 1992, 1993; Tang and Yang, 1993).

After collision, the main stream of the KC turns northeastward almost along the line of shelf break, defined as the $200 \mathrm{~m}$ isobath (Nitani, 1972). However, part of the KC water intrudes onto the shelf (see Figs. $2 \mathrm{a}$ and $3 \mathrm{a}$ ) forming a branch current, termed the Kuroshio Branch Current (KBC). On the western side of the KBC, a cyclonic eddy about $70 \mathrm{~km}$ in diameter is generated over the shelf-slope as a result of the westerly deflection of part of the KBC. The eddy water has similar hydrographic properties to Kuroshio water in the deeper water column and to the mixed water between Kuroshio and the shelf water in the upper water column (Tang et al., 1998). A southwestward to southeastward countercurrent usually spans over the whole water column along the Mien-hua Canyon (MHC) (Hsueh et al., 1993; Tang and Yang, 1993) and is identified as a part of the eddy (Tang et al., 1998). An upwelling develops somewhere around the shelf break through the uplifting of intruded Kuroshio water (Fan 1980; Liu et al., 1992; Lin et al., 1992). The upwelling brings up sufficient nutrients (Liu et al., 1992) enhancing the chlorophyll $a$ and primary productivity (Chen, 1992; Gong et al., 1997). The eddy, however, is significant only in summer (late April to mid-September). In winter, the KC may extensively intrude onto the shelf due to 

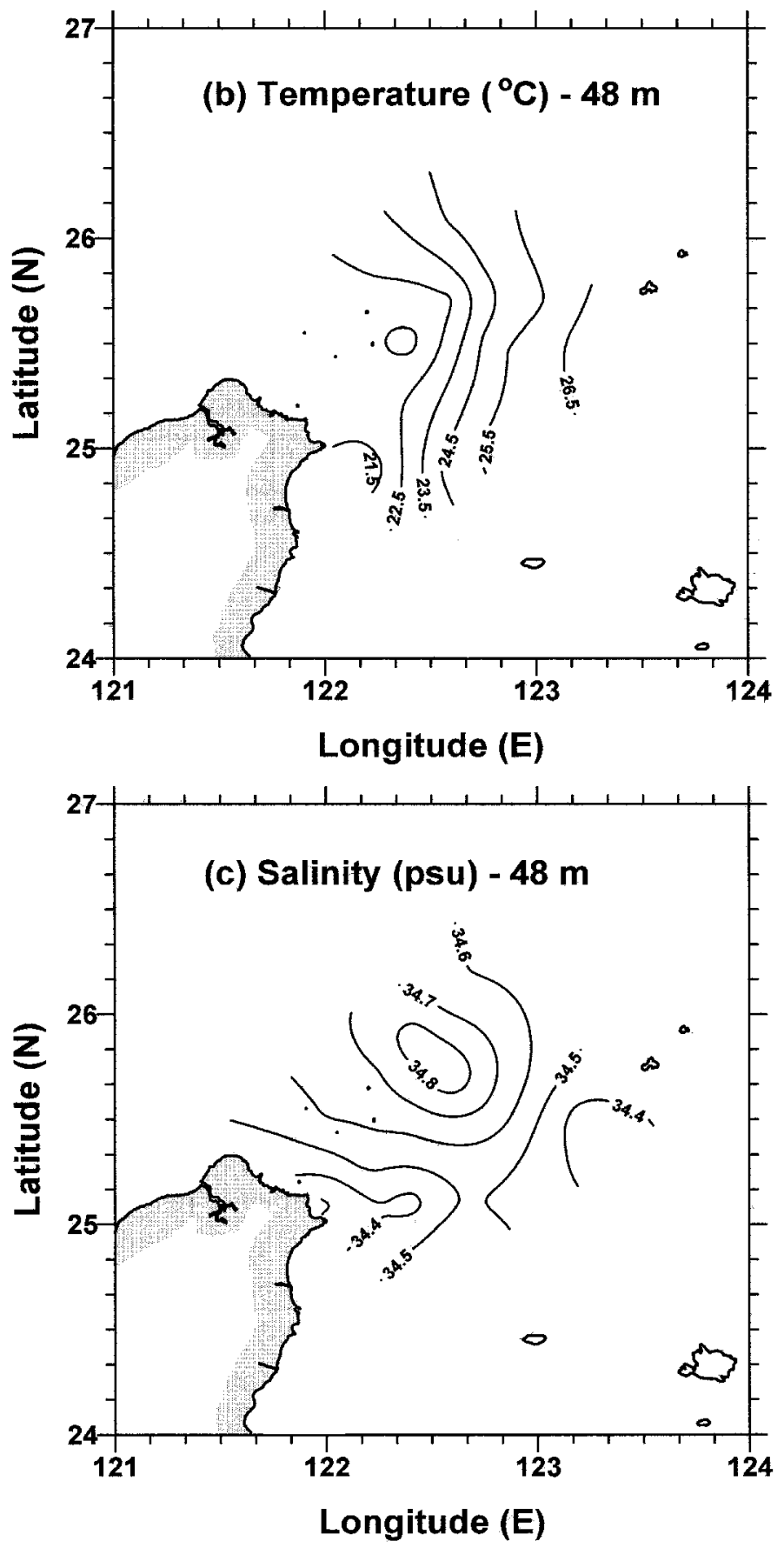

Figure 3. (Continued) 
the cooling effect (Hsueh et al., 1993), and the eddy and the countercurrent would disappear above $150 \mathrm{~m}$ (Tang et al., 1998).

In addition, a southeastward filament (a small alongshore flow) occasionally appears somewhere between the eddy and northern Taiwan. It has the hydrographic properties of water from the continental shelf water and the Kuroshio subsurface water which have mixed, and perhaps originates from the Taiwan Strait water (Chern et al., 1990; Liu et al., 1992; Hsueh et al., 1992; Tang et al., 1998). The outflow may incorporate the mixed water into the KC main stream, and the mixed water would recycle back onto the shelf with the on-shelf intrusion (Liu et al., 1992; Tang et al., 1998). Tang et al. (1998) further state that its occurrence is mainly driven by the completion of the northward outflow from Taiwan Strait (TWC) with a counterclockwise eddy off the northwestern tip of Taiwan.

\section{Materials and methods}

Samples of seawater for particulate metal analysis were taken from the southern ECS off northeastern Taiwan during August 1994 (summer is the most important season for terrigenous sediment export) on board National Taiwan University's R/V Ocean Researcher I. This cruise was conducted three days after landfall of typhoon Doug on northern Taiwan. Although the level of suspension was higher than usual, the circulation patterns were not affected during this time. The study can still demonstrate the influence of the eddy on the distribution of lithogenic particulates.

Water samples were collected using 20 liter GO-FLO bottles on a CTD rosette and taken along three NE-SW parallel transects containing 15 hydrographic stations (Fig. 1); the three transects crossed over the continental shelf, slope and the OT. The sampling sites mainly followed the CTD measuring sites. Seawater samples $(n=92)$ were taken from the water column at varying depths.

When the seawater was recovered, it was carefully transferred to a 20 liter pre-cleaned plastic bottle. The water sample was then pressure filtered through a pre-cleaned and pre-weighed $142 \mathrm{~mm}-0.4 \mu \mathrm{m}$ Nuclepore polycarbonate filter using a Satorius PTFE pressure filter holder and a Masterflex ${ }^{\circledR}$ wriggle pump; one liter of distilled deionized water was then passed through the filter to remove residual salts. In most cases 20 liters of seawater were used to make a particulate sample, but in some cases 40 liters were used. Filters were stored in pre-cleaned plastic dishes and refrigerated for later digestion.

Particulate-laden filters were processed by the total digestion method using Suprapur $\mathrm{HF}, \mathrm{HNO}_{3}$ and $\mathrm{HClO}_{4}$ (all from Merck), and the solutions were analyzed for $\mathrm{Al}$ and other trace metals, of which only the $\mathrm{Al}$ data are reported here since $\mathrm{Al}$ is a good indicator element of lithogenic particles (Masuzawa et al., 1989; Windom and Gross, 1989; Brugmann et al., 1992). Metal analysis was made with a Hitachi Z8100 flameless atomic absorption spectrophotometer (graphite furnace) equipped with a Zeeman correction system. Metal concentrations were quantified by calibrations against standard BCSS-1 reference sample. The precision for $\mathrm{Al}$ determination was better than $10 \%$.

On the same cruise, during the TSM sampling August 1994, a concurrent investigation 
of the current fields over the seas off northeastern Taiwan was conducted with the Shipboard Acoustic Doppler Current Profiler (Sb-ADCP) (Tang et al., 1998). A hydrographic survey (Fig. 1) was also made using a Sea-Bird Conductivity-Temperature-Depth (CTD) instrument. The measurements of current and hydrography were duplicated after a time interval of 68.31 hours, 5.5 times the period of the $M_{2}$ tide. The phase-averaging of measurements was used to eliminate high-frequency noise which is dominated by the $M_{2}$ tide.

\section{Results and discussion}

\section{a. Current fields and hydrography}

Figures 2 and 3 present the current, temperature and salinity fields. In this study, 0-16 m depths are designated as the surface layer, and 30-50 m depths are designated as the subsurface layer. In Figures $2 \mathrm{a}$ and $3 \mathrm{a}$, the circulation patterns over the study area can be clearly seen, and the major components are the main stream of the $\mathrm{KC}$, the $\mathrm{KBC}$, the cyclonic eddy and possibly the filament. From the two current fields $(16 \mathrm{~m}$ and $48 \mathrm{~m}$ in depth), the eddy center is possibly located somewhere between Sta. 7 and Sta. 11. Sta. 11 is located in the lower salinity patches of salinity fields at the surface layer (Fig. 2c), that may be due to the entrainments of less saline coastal water by the eddy (Simpson et al., 1984; Simpson and Lynn, 1990). The results indicate that the eddy center is possibly located in the vicinity of Sta. 11. In Figures $2 b, 2 c, 3 b$ and 3c, water of a lower temperature and salinity exists immediately off northern Taiwan, probably indicating the Taiwan-derived river runoff (e.g., the Tanshui and Lanyang Rivers). The detailed description and discussion of the current field and hydrography of the cruise have been given elsewhere (Tang et al., 1998).

\section{b. PAl concentrations and distributions}

All data for particulate $\mathrm{Al}(\mathrm{PAl})$ concentrations in seawater are presented in Table 1 and the depth variations at each station are displayed in Figure 4. It is noted that the locations with higher surface $(5 \mathrm{~m})$ and subsurface $(30-50 \mathrm{~m}) \mathrm{PAl}$ concentrations are at Stas. 1, 3, 4, 6, 11; among them Stas. 1, 3 and 4 are closest to Taiwan and the station line 3, 6 and 11 points to the eddy center. It can also be seen that the PAl concentration increases near the bottom are found at many stations (e.g. Stas. 1, 4, 5, 11, 14, 19 and 20), indicating that sediment resuspension commonly takes place over the study area, especially on the slope area.

PAl ranges from 0.2 to $35.1 \mu \mathrm{g} / \mathrm{l}$ in surface water and from 0.7 to $48.5 \mu \mathrm{g} / \mathrm{l}$ in subsurface water (Table 1). This reveals that the PAl concentrations are comparable in both water layers. Since the sampling for this study was done three days after a typhoon landing upon Taiwan, the PAl concentrations measured in this study are much higher than those measured in early October 1993, the latter being $0.67-4.88 \mu \mathrm{g} / \mathrm{l}$ in surface water and 0.99-20.5 $\mu \mathrm{g} / \mathrm{l}$ in subsurface water (Shaw, 1994). 


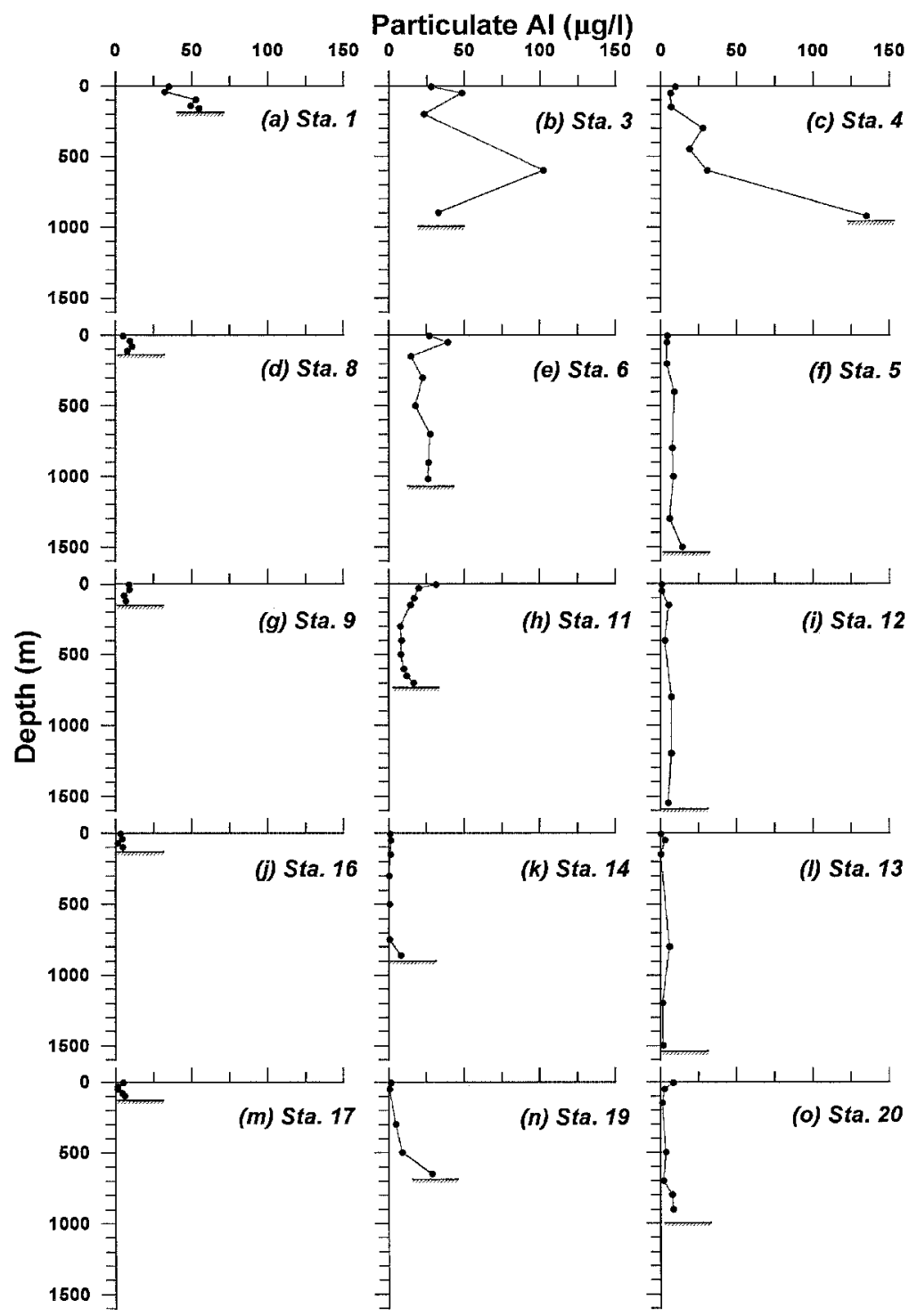

Figure 4. Vertical profiles of particulate $\mathrm{Al}(\mathrm{PAl})$ concentrations for 15 hydrographic stations.

The horizontal distributions of PAl in surface and subsurface water are shown in Figure 5. In both layers, the distribution patterns of PAl display an $\Omega$-like shape with high concentrations at the opening toward the Taiwan coast (Fig. 5). It is also noted that $6 \mu \mathrm{g} / \mathrm{l}$ $\mathrm{PAl}$ contours in the two water layers occur at almost the same position, which matches the western boundary of the KC and KBC (see Figs. 2a, 3a and 5). On the seaward side of the $6 \mu \mathrm{g} / \mathrm{l}$ contour, there are lower but uniform PAl contents in both water layers. The results 
Table 1. Data of PAl concentrations in the water column of 15 hydrographic stations.

\begin{tabular}{|c|c|c|c|c|c|}
\hline Station no. & Depth (m) & $\mathrm{Al}(\mu \mathrm{g} / \mathrm{l})$ & Station no. & Depth (m) & $\mathrm{Al}(\mu \mathrm{g} / \mathrm{l})$ \\
\hline 1 & 5 & 35.1 & 11 & 400 & 8.8 \\
\hline 1 & 40 & 32.4 & 11 & 500 & 8.0 \\
\hline 1 & 100 & 52.8 & 11 & 600 & 10.2 \\
\hline 1 & 140 & 49.5 & 11 & 650 & 11.9 \\
\hline 1 & 160 & 54.7 & 11 & 700 & 16.5 \\
\hline 3 & 5 & 28.2 & 12 & 5 & 1.0 \\
\hline 3 & 50 & 48.5 & 12 & 50 & 0.9 \\
\hline 3 & 200 & 23.1 & 12 & 150 & 5.3 \\
\hline 3 & 600 & 102.4 & 12 & 400 & 2.9 \\
\hline 3 & 900 & 32.7 & 12 & 800 & 7.2 \\
\hline 4 & 5 & 9.5 & 12 & 1200 & 7.2 \\
\hline 4 & 50 & 6.7 & 12 & 1550 & 5.2 \\
\hline 4 & 150 & 6.8 & 13 & 5 & 0.2 \\
\hline 4 & 300 & 27.8 & 13 & 50 & 3.1 \\
\hline 4 & 450 & 19.1 & 13 & 150 & 0.3 \\
\hline 4 & 600 & 30.7 & 13 & 800 & 6.0 \\
\hline 4 & 920 & 135.0 & 13 & 1200 & 1.4 \\
\hline 5 & 5 & 4.3 & 13 & 1500 & 1.8 \\
\hline 5 & 50 & 4.3 & 14 & 5 & 1.1 \\
\hline 5 & 200 & 4.2 & 14 & 50 & 1.5 \\
\hline 5 & 400 & 8.9 & 14 & 150 & 1.4 \\
\hline 5 & 800 & 7.8 & 14 & 300 & 0.3 \\
\hline 5 & 1000 & 8.2 & 14 & 500 & 0.7 \\
\hline 5 & 1300 & 5.8 & 14 & 750 & 0.6 \\
\hline 5 & 1500 & 14.5 & 14 & 860 & 8.2 \\
\hline 6 & 5 & 26.9 & 16 & 5 & 3.3 \\
\hline 6 & 50 & 39.1 & 16 & 40 & 4.6 \\
\hline 6 & 150 & 14.6 & 16 & 70 & 1.5 \\
\hline 6 & 300 & 22.5 & 16 & 100 & 4.9 \\
\hline 6 & 500 & 17.5 & 17 & 5 & 5.1 \\
\hline 6 & 700 & 27.4 & 17 & 30 & 1.7 \\
\hline 6 & 900 & 26.3 & 17 & 50 & 1.5 \\
\hline 6 & 1020 & 26.0 & 17 & 80 & 4.5 \\
\hline 8 & 5 & 5.1 & 17 & 100 & 6.0 \\
\hline 8 & 40 & 9.8 & 19 & 5 & 1.5 \\
\hline 8 & 80 & 11.0 & 19 & 50 & 0.7 \\
\hline 8 & 110 & 8.0 & 19 & 300 & 5.0 \\
\hline 9 & 5 & 9.1 & 19 & 500 & 8.9 \\
\hline 9 & 40 & 9.4 & 19 & 650 & 28.8 \\
\hline 9 & 80 & 5.9 & 20 & 5 & 8.4 \\
\hline 9 & 120 & 6.9 & 20 & 50 & 2.6 \\
\hline 11 & 5 & 31.5 & 20 & 150 & 1.3 \\
\hline 11 & 30 & 19.9 & 20 & 500 & 3.7 \\
\hline 11 & 100 & 16.7 & 20 & 700 & 2.2 \\
\hline 11 & 150 & 14.3 & 20 & 800 & 7.8 \\
\hline 11 & 300 & 7.8 & 20 & 900 & 8.5 \\
\hline
\end{tabular}



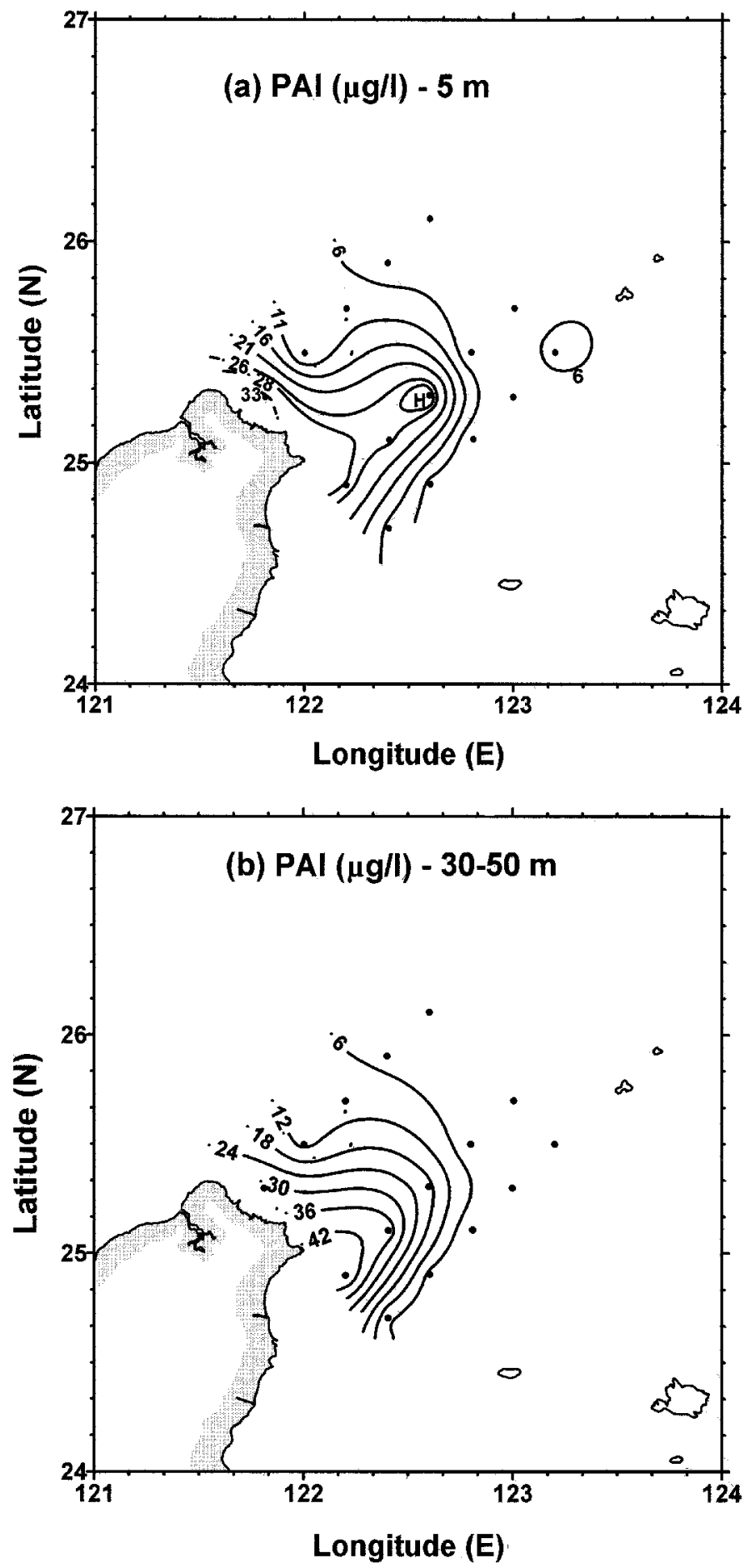

Figure 5. Contour plots of particulate $\mathrm{Al}(\mathrm{PAl})$ in (a) surface (5 m) and (b) subsurface (30-50 m) water. 
lead to the postulation that the value of $6 \mu \mathrm{g} / \mathrm{l}$ might represent the minimum concentration of the upper ECS shelf water or the maximum concentration of the intruded clear Kuroshio water for PAl. Nevertheless, in surface water the highest PAl appears at Sta. 1; whereas in subsurface water, the highest PAl appears at Sta. 3, both stations being the closest to Taiwan. In surface water, the next highest PAl is seen at Sta. 11, where it is regarded as the eddy center. However, at Sta. 20 a slightly higher value of PAl is found, and this could be considered a local input from the nearby small islands.

According to the distributions of PAl which is usually regarded as an indicator element for crustal components in various solid particles (e.g., Masuzawa et al., 1989; Windom and Gross, 1989; Brugmann et al., 1992), transport pathways of lithogenic components in this study area can be drawn.

\section{c. Sources and transport of lithogenic particles}

As described above, Sta. 1 and Sta. 3, closest to Taiwan, exhibit lower temperature and salinity (Fig. 2b, 2c and Fig. 3b, 3c) in the upper water layer, indicating that cold fresh river water discharges into the sea from Taiwan and mixes with warm saline Kuroshio water. As a consequence, high loads of terrigenous particles and pollutants must be exported and introduced into the sea by the river runoff, especially in summer (Milliman, 1991; Kao and Liu, 1996). Therefore, the introduction of riverborne particulates from eastern and northern Taiwan could result in the high levels of lithogenic particles in surface and subsurface water such as the PAl observed at Sta. 3 and Sta. 1 (Fig. 5). Besides terrigenous sources in northern and eastern Taiwan, two other sources need to be considered: one, the suspended loads carried by the TWC flowing northward along the western coast of Taiwan; the other, the suspended loads carried by the CCC flowing southward along the China coast (Fig. 1 inset).

According to the distribution of suspended particulates in both surface and near-bottom waters of the Changjiang estuary during summer, Milliman et al. (1985) suggested that these particles might be transported southward by the Jiangsu Coastal Current (a part of the $\mathrm{CCC}$ ) and that the dynamic interaction between the muddy coastal current and the clearer offshore TWC might result in the sharp east-west gradients of the TSM concentrations. This means that the TWC can efficiently interrupt the offshore transport of Changjiang suspended particles to the Taiwan offshore area even though they are transported southward (Milliman et al., 1989). However, because our study area did not extend to the Mainland China coast, we cannot conclude with certainty whether the escaped eastward TSM is a significant contribution to the high PAl in the upper water observed at Sta. 1. In contrast, the TWC flows northward in Taiwan Strait along the west coast of Taiwan. Several rivers on western Taiwan discharge large quantities of suspended sediments (191 Mt/yr) with high runoff occurring especially in the summer rainy season (Water Resources Bureau, 1997). By reasonable inference, the northward TWC would carry more or less suspended particulates through Taiwan Strait toward the area offshore from northwestern Taiwan, although no research has previously been conducted in this area. 
When the TWC reaches the area offshore from northern Taiwan, part of the TWC water occasionally turns southeastward along the northern shore of Taiwan becoming a filament (Chern et al., 1990; Liu et al., 1992; Tang et al., 1998). Consequently, material carried by it might be subject to transportation by the filament.

The $\Omega$-shaped patterns of PAl distributions in the upper water (Fig. 5a and 5b), suggest that the transport of PAl is mainly driven by the cyclonic eddy. Once the riverine suspended materials, from either northern or eastern Taiwan, carried by transport agents reached the eddy periphery, then the cyclonic rotation of the eddy would subsequently draw the dispersed particles into its circulation and gradually into its center to accumulate. The observed high PAl (or lithogenic particles) in the surface water of the eddy center is therefore attributed to the entrainment of terrigenous particulates from the eddy perimeter followed by accumulation. However, in the surface layer of the eddy center there exists an elevated PAl, whereas the subsurface layer has no comparably high PAl (Fig. 5).

At Sta. 11, near the eddy center, the vertical variation of PAl shown in Figure 4h illustrates that PAl decreases with depth for the upper $500 \mathrm{~m}$ and then increases toward the sea bottom. The increase toward the sea bottom is due to sediment resuspension, while the decrease in the upper $500 \mathrm{~m}$ is due to the removal process. In addition, the nutrient-rich upwelled water enhances primary production around the eddy center (Liu et al., 1992; Chen, 1992; Gong et al., 1997). The abundant biogenic material (e.g., plankton debris, fecal pellets) may accelerate the removal of fine lithogenic particles via coagulation and aggregation between biogenic and lithogenic particles (Turekian, 1977; Lal; 1980; Deuser et al., 1983). Hence, such rapid removal may account for the presence of a PAl maximum in the upper layer and an absence of a relative maximum in the lower layer around the eddy center.

Additionally, the close spacing contours of PAl around the eddy (Fig. 5) suggest that either rapid removal of lithogenic particles or dilution of high PAl coastal water by clearer upwelled subsurface Kuroshio water occurs. When the lithogenic particle-rich coastal water mixed with the biogenic particle-rich eddy water, the mixing processes would lead to a dilution of lithogenic particulates in the water, creating a sharp gradient of PAl around the eddy. In addition, the positions of the $6 \mu \mathrm{g} / \mathrm{l}$ contour of PAl almost match the western boundary of the $\mathrm{KC}$ (including the main stream along the east shore of Taiwan and the branch current on the ECS shelf-slope) (compare Fig. 5 with Fig. 2a and Fig. 3a); the $6 \mu \mathrm{g} / 1$ contour seems to exactly separate the region into two: one with high but variable PAl to the west and the other with low but uniform PAl to the east. This phenomenon indicates that at high speed the $\mathrm{KC}$ would become a barrier to offshore transport of terrigenous particulates. Lin and Chen (1983) studied the grain sizes and mineralogy of southern OT surface sediments, and suggested that the KC sweeping at high speed across the western OT acted as a barrier to confine the Taiwan-derived sediments to the inshore area and to prevent them from being transported farther east and north. In addition, on the seaward side of the KBC over the ECS slope-shelf, the low (smaller than $6 \mu \mathrm{g} / \mathrm{l}$ ) but uniform PAl is clearly seen and essentially reflects the oligotrophic and clear characteristics of the Kuroshio water. 


\section{d. A conceptual transport model for lithogenic particles}

From the horizontal and vertical distribution patterns of PAl, a conceptual transport model for the lithogenic particles in the seas off northeastern Taiwan is proposed. The model is simply schemed in Figure 6 which illustrates how the cyclonic eddy drives the distribution of lithogenic particles. In this model, the main sources of lithogenic particles in the upper water are the riverborne materials exported from Taiwan. Although two other sources of lithogenic particles from Taiwan Strait and the Mainland China coast are also possible, we cannot identify with certainty their importance in the pronounced high PAl observed in the water column off northern Taiwan.

On the shelf off northern Taiwan (at about point $a$ in Fig. 6), the flow of suspended particles takes two routes: one goes northeastward and the other southeastward. The northeastward particles would be involved in the eddy circulation. In contrast, the southeastward particles would combine with the particles discharged from eastern Taiwan (Lanyang River runoff) (at about point $b$ in Fig. 6) and merge into the northward KC. Upon reaching the upper slope off northeastern Taiwan, these particles are then carried northward by the current and flow toward the eddy. Once the lithogenic particles are carried to the periphery of the eddy, the cyclonic rotation would draw them into the center to accumulate. In addition, the main stream and branch of the $\mathrm{KC}$ would act as a barrier by interrupting the flow of lithogenic particles beyond the eddy. Overall, the distribution and transport of the lithogenic particles in the upper water layer off northeastern Taiwan is controlled by the transport agents of the cyclonic eddy circulation and the KC (including the main stream along eastern Taiwan and the branch across the ECS shelf-slope) as well as a filament along the northern Taiwan coast.

Large quantities of terrigenous particles and heavy metals may be introduced into the study area, and the eddy perhaps acts as an important conduit for seaward transport of these materials. In the eddy center, abundant marine organisms would produce vast biological remains (e.g., biogenic debris and fecal pellets). In particular, fecal pellets in seawater generally prove to be the main agents for rapid removal of these lithogenic particles and particle-reactive metals (Turekian, 1977; Deuser et al., 1983).

The depth profile of PAl at Sta. 11 (Fig. 4h) displays a decreasing trend with depth in the top $500 \mathrm{~m}$ and an increase near the sea bottom, manifesting the removal occurring in the upper water column and the addition from resuspension in the lower water column. Li (1994) proposed a flux model and suggested that the dissolved particle-reactive metals in the ECS shelf water could be efficiently sequestered by suspended particles and subsequently removed from the water column to the bottom sediments. Liu et al. (1995) calculated the residence time for the particulate organic carbon in the euphotic zone (70-90 m) of the upwelling region to be 3-8 days. By using the sediment traps deployed at one station near the eddy center, Wei (1995) estimated the residence times of the settling particles and particulate ${ }^{210} \mathrm{~Pb},{ }^{210} \mathrm{Po}$ and ${ }^{234} \mathrm{Th}$ in the upper $60 \mathrm{~m}$ to be $4.5-11,1.8-5.7$, 6.4-11.3 and 2.5-4.9 days, respectively. Hence, we can expect that there are high sedimentation rates beneath the eddy center. However, it is surprising that the sedimenta- 


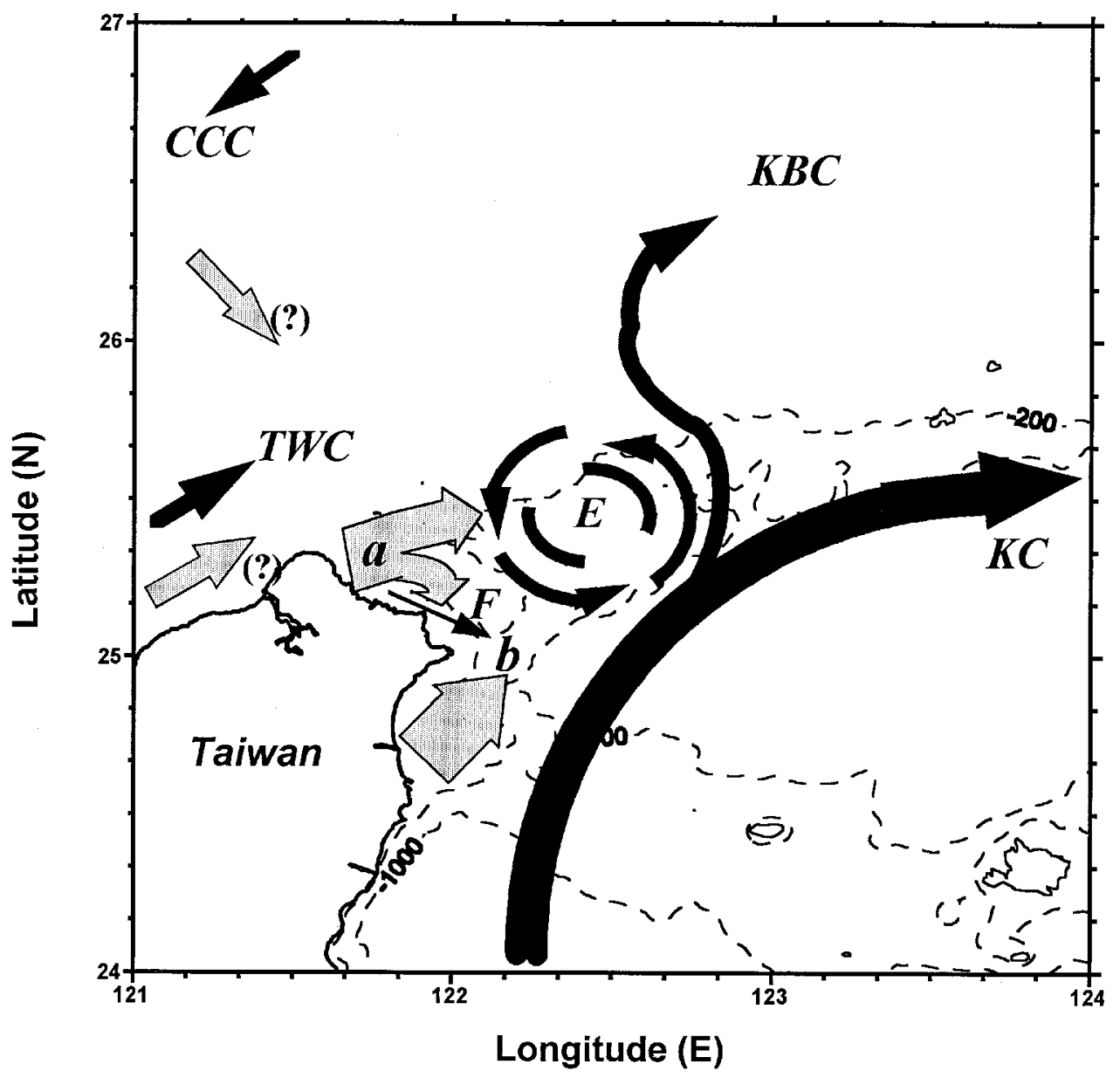

Figure 6. Scheme of the proposed transport model of terrigenous lithogenic particles suspended in the upper layer (shallower than $50 \mathrm{~m}$ ) off northeastern Taiwan. The regional circulation patterns are also plotted and denoted by solid arrows: 1, main stream of the Kuroshio Current $(K C) ; 2$, Kuroshio Branch Current $(K B C)$ on the East China Sea (ECS) shelf; 3, cyclonic eddy $(E)$ on the ESC shelf break; 4, filament $(F)$ between the eddy and northern Taiwan; 5, Taiwan Warm Current $(T W C$ ); and 6, Changjiang Coastal Current (CCC) (or Jiangsu Coastal Current). The widths of solid arrows roughly represent the relative magnitude of circulation. The stippled arrows represent the probable regional sources of suspended particles in both surface and subsurface water off northeast Taiwan. The shaded arrows indicate the predominant transport direction of terrigenous particles, and the arrow sizes approximately reflect only the local strength of suspended lithogenic particles. Point $a$ is the place where lithogenic particle-rich coastal water flow divides into two; point $b$ is the place where the southeastward outflow (F) along the northern shore of Taiwan merges into the northward $\mathrm{KC}$. 


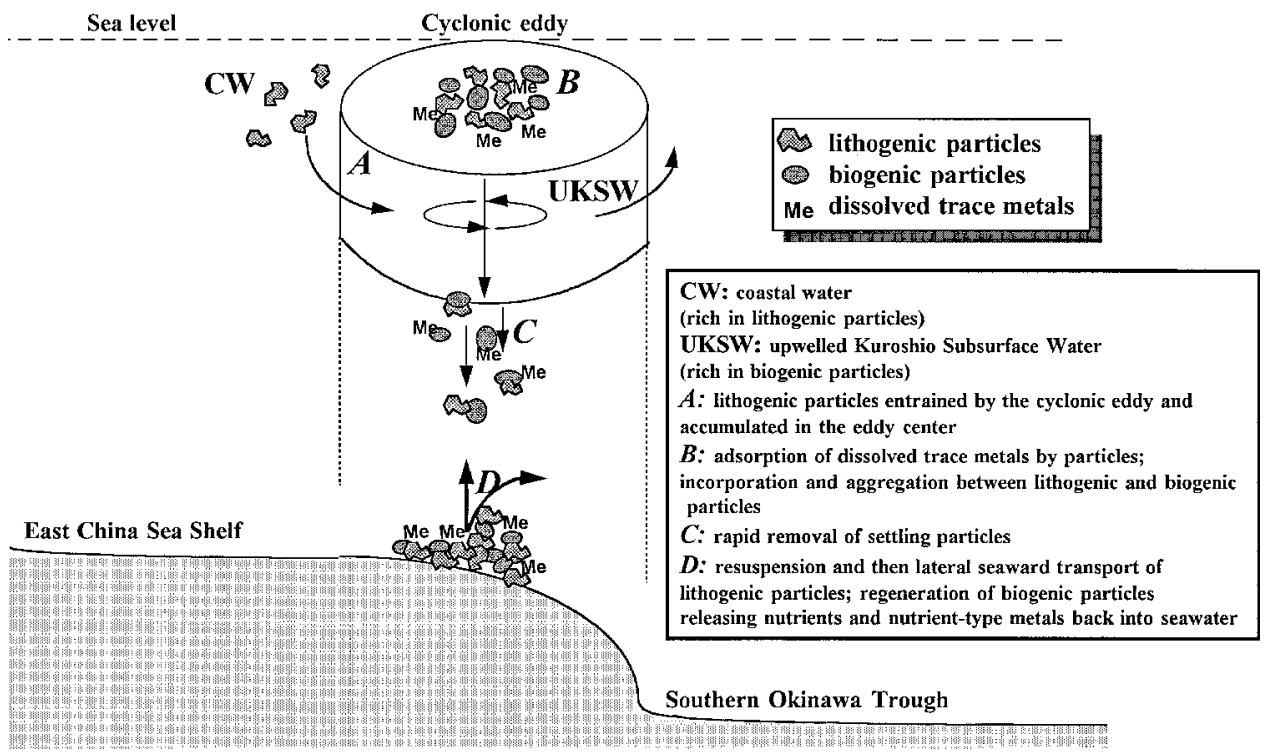

Figure 7. Scheme of a series of interactions and sequential transport for lithogenic particulates and biogenic material probably occurring throughout the water column around the eddy, illustrating that the eddy may be an important conduit for transporting suspended sediments on the East China Sea shelf and slope to the southern Okinawa Trough.

tion rates, using ${ }^{210} \mathrm{~Pb}$ dating, at stations near the eddy center on the upper slope are non-detectable, whereas rates of $0.37 \mathrm{~cm} / \mathrm{yr}$ have been found on the lower slope (deeper than Sta. 11 or $\sim 1000 \mathrm{~m}$ ) (Chung and Chang, 1995). Chung and Chang (1995) further suggested that the high ${ }^{210} \mathrm{~Pb}$ sediments bypassing the shelf and upper-middle slope to lower slope region and the southern OT were probably one major source accounting for the high ${ }^{210} \mathrm{~Pb}$ fluxes observed on the lower slope and the southern OT sediments. Therefore, it is thought that lateral seaward transport coupled with frequent sediment resuspension (see Fig. 4) is responsible for such dramatic variability of sedimentation rates in the upper and lower slope sediments, even though large quantities of particles are removed throughout the eddy water column on the upper to middle slope region. In turn, when these depositing sediments reach the seabed, they are then subject to resuspension and lateral transport toward the OT. Thus, there is little contemporary sediment deposited on the upper and middle slope. This phenomenon is quite different from those observed on the ECS shelf, where mud patches are usually observed beneath the cyclonic gyres ( $\mathrm{Hu}, 1984$; Qu and $\mathrm{Hu}$, 1993). It is consequently suggested that the eddy may be an important agent for sediment transport from the shelf and upper slope to the trough off northeastern Taiwan. This is a valuable example to elucidate the role of eddy systems in sediment transport in coastal oceans. The overall processes possibly involved in lithogenic particles occurring in the cyclonic eddy are schemed in Figure 7. 
Acknowledgments. We are grateful to the two anonymous reviewers for their constructive comments. We thank the technicians and crew of R/V Ocean Researcher I for help with sampling. Thanks are also extended to Messrs. K. Huang and J. H. Tai for pretreatment of samples and data processing. This work was supported by National Science Council (R.O.C.) grants NSC 84-2611M002A-007K2 and NSC 85-2611-M002A-026K2 to F.J.L. and NSC 85-2611-M-002A-019-K2 to T.Y.T.

\section{REFERENCES}

Aristegui, J., P. Tett, A. Hernandez-Guerra, G. Basterretxea, M. F. Montero, K. Wild, P. Sangra, S. Hernandez-Leon, M. Canton, J. A. Garcia-Braun, M. Pacheco and E. D. Barton. 1997. The influence of island-generated eddies on chlorophyll distribution: a study of mesoscale variation around Gran Canaria. Deep-Sea Res., 44, 71-96.

Bishop, J. K. B., M. H. Conte, P. H. Wiebe, M. R. Roman and C. Langdon. 1986. Particulate matter production and consumption in deep mixed layers: observations in a warm-core ring. Deep-Sea Res., 33, 1813-1841.

Bishop, J. K. B. and T. M. Joyce. 1986. Spatial distributions and variability of suspended particulate matter in warm-core ring 82B. Deep-Sea Res., 33, 1741-1760.

Brugmann, L., P. C. Bernard and R. Grieken. 1992. Geochemistry of suspended matter from the Baltic Sea, 2. Results of bulk trace metal analysis by AAS. Mar. Chem., 38, 303-323.

Chen, Y. L. 1992. Summer phytoplankton community structure in the Kuroshio current-related upwelling northeast of Taiwan. Terres. Atmos. Ocean. Sci., 3, 305-320.

Chern, C. S., J. Wang and D. P. Wang. 1990. The exchange of Kuroshio and the East China Sea shelf water. J. Geophys. Res., 95, 16,017-16,023.

Chung, Y. and W. C. Chang. 1995. Pb-210 fluxes and sedimentation rates on the lower continental slope between Taiwan and the South Okinawa Trough. Cont. Shelf Res., 15, 149-164.

Deuser, W. G., P. G. Brewer, T. D. Jickells and R. F. Commeau. 1983. Biological control of the removal of abiogenic particles from the surface ocean. Science, 219, 388-391.

Falkowski, P. G., D. Ziemman, Z. Kolber and P. K. Bienfang. 1991. Role of eddy pumping in enhancing primary production in the ocean. Nature, 352, 55-58.

Fan, K. L. 1980. On upwelling off northeastern shore of Taiwan, Acta Oceanogr. Taiwanica, 11, $105-117$.

Gong, G. C., F. K. Shiah, K. K. Liu, W. S. Chuang and J. Chang. 1997. Effect of the Kuroshio intrusion on the chlorophyll distribution in the southern East China Sea during spring 1993. Cont. Shelf Res., 17, 79-94.

Haidvogel, D. B., A. R. Robinson and C. G. H. Rooth. 1983. Eddy-induced dispersion and mixing, in Eddies in Marine Science, A. R. Robinson, ed., Springer-Verlag, Berlin, 481-491.

Hayward, T. L. and A. W. Mantyla. 1990. Physical, chemical and biological structure of a coastal eddy near Cape Mendocino. J. Mar. Res., 48, 825-850.

Honjo, S., S. J. Manganini and L. J. Poppe. 1982. Sedimentation of lithogenic particles in the deep ocean. Mar. Geol., 50, 199-220.

Hsueh, Y., C. S. Chern and J. Wang. 1993. Blocking of the Kuroshio by the continental shelf northeast of Taiwan. J. Geophys. Res., 98, 12,351-12,359.

Hsueh, Y., J. Wang and C. S. Chern. 1992. The intrusion of the Kuroshio across the continental shelf northeast of Taiwan. J. Geophys. Res., 97, 14,323-14,330.

Hu, D. C. 1984. Upwelling and sedimentation dynamics. Chin. J. Oceanol. Limnol., 2, 12-19.

Kao, S. J. and K. K. Liu. 1996. Particulate organic carbon export from a subtropical mountainous river (Lanyang Hsi) in Taiwan. Limnol. Oceanogr., 41, 1749-1757. 
Lal, D. 1980. Comments on some aspects of particulate transport in the oceans. Earth Planet. Sci. Lett., 49, 520-527.

Li, Y. H. 1976. Denudation of Taiwan Island since the Pliocene epoch. J. Geol., 4, 105-107.

1994. Material exchange between the East China Sea and the Kuroshio Current. Terres. Atmos. Ocean. Sci., 5, 625-631.

Lin, C. Y., C. Z. Shyu and W. H. Shih. 1992. The Kuroshio fronts and cold eddies off northeastern Taiwan observed by NOAA-AVHRR imageries. Terres. Atmos. Ocean. Sci., 3, 225-242.

Lin, F. J. and J. C. Chen. 1983. Textural and mineralogical studies of sediments from the southern Okinawa Trough. Acta Oceanogr. Taiwanica, 14, 26-41.

Liu, K. K., G. C. Gong, C. Z. Shyu, S. C. Pai, C. L. Wei and S. Y. Chao. 1992. Response of Kuroshio upwelling to the onset of northeast monsoon in the sea north of Taiwan: Observation and a numerical simulation. J. Geophys. Res., 97, 12,511-12,526.

Liu, K. K., Z. L. Lai, G. C. Gong and F. K. Shiah. 1995. Distribution of particulate organic matter in the southern East China Sea: Implications in production and transport. Terres. Atmos. Ocean. Sci., 6, 27-45.

Masuzawa, T., S. Noriki, T. Kurosaki, S. Tsunogai, M. Koyama. 1989. Compositional change of settling particles with water depth in the Japan Sea. Mar. Chem., 27, 61-78.

McCarthy, J. J. and J. L. Nevins. 1986. Utilization of nitrogen and phosphorus by primary producers in warm-core ring 82-B following deep convective mixing. Deep-Sea Res., 33, 1773-1788.

Milliman, J. D. 1991. Flux and fate of fluvial sediment and water in coastal seas, in Ocean Margin Processes in Global Change, R. F. C. Mantoura, J. M. Martin and R. Wollast, eds., 69-89.

Milliman, J. D. and R. H. Meade. 1983. World-wide delivery of river sediment to the oceans. J. Geol., 91, 1-21.

Milliman, J. D., Y. Qin and Y. A. Park. 1989. Sediments and sedimentary processes in the Yellow and East China Seas, in Sedimentary Facies in the Active Plate Margin, A. Taira and F. Masuda, eds., 233-249.

Milliman, J. D., H. T. Shen, Z. S. Yang and H. M. Robert. 1985. Transport and deposition of river sediments in the Changjiang estuary and adjacent continental shelf. Cont. Shelf Res., 4, 37-45.

Nelson, D. M., H. W. Ducklow, G. L. Hitchcock and M. A. Brzezinski. 1985. Distribution and composition of biogenic particulate matter in a Gulf Stream warm-core ring. Deep-Sea Res., 32, 1347-1369.

Nitani, H. 1972. Beginning of the Kuroshio, in Kuroshio, Physical Aspects of the Japan Current, H. Stommel and K. Yoshida, eds., University of Washington Press, Seattle, 129-163.

Qu, T. and D. Hu. 1993. Upwelling and sedimentation dynamics II: A simple model. Chin. J. Oceanol. Limnol., 11, 289-295.

Robinson, A. R. 1983. Overview and summary of eddy science, in Eddies in Marine Science, A. R. Robinson, ed., Springer-Verlag, Berlin, 3-15.

Shaw, L. M. 1994. Distribution and transport of particulate metals in the water and sediment columns along the shelf and slope off northeast Taiwan (in Chinese). Master's thesis, National Taiwan University, $88 \mathrm{pp}$.

Simpson, J. J., C. J. Koblinsky, L. R. Haury and T. D. Dickey. 1984. An offshore eddy in the California Current System. Prog. Oceanog., 13, 1-111.

Simpson, J. J. and R. J. Lynn. 1990. A mesoscale eddy dipole in the offshore California Current. J. Geophys. Res., 95, 13,009-13,022.

Smith, C. L., K. J. Richards and M. J. R. Fasham. 1996. The impact of mesoscale eddies on plankton dynamics in the upper ocean. Deep-Sea Res., 43, 1807-1832.

Tang, T. Y., Y. Hsueh, Y. J. Yang and J. C. Ma. 1998. Continental slope flow northeast of Taiwan. J. Phys. Oceanogr. (in press). 
Tang, T. Y. and Y. J. Yang. 1993. Low frequency current variability on the shelf break northeast of Taiwan. J. Oceanogr., 49, 193-210.

The Ring Group. 1981. Gulf Stream cold-core rings: Their physics, chemistry, and biology. Science, 212, 1091-1100.

Turekian, K. K. 1977. The fate of metals in the oceans. Geochim. Cosmochim. Acta, 41, 1139-1144.

Water Resources Bureau. 1997. Hydrological Year Book of Taiwan, Republic of China, 1995, Ministry of Economic Affairs, Taipei, Taiwan, R.O.C. 400 pp.

Wei, C. L. 1995. Particle dynamics and transport processes in euphotic zone of the East China Sea (in Chinese), in Workshop for Integrated Oceanographic Research Programs, K51-K59.

Wiebe, P. H. and T. J. McDougall. 1986. Introduction to a collection of papers on warm-core rings. Deep-Sea Res., 33, 1455-1457.

Windom, H. L. and T. F. Gross. 1989. Flux of particulate aluminum across the southern U.S. continental shelf. Estuar. Coast. Shelf Sci., 28, 327-338.

Wolanski, E. and W. M. Hamner. 1988. Topographically controlled fronts in the ocean and their biological influence. Science, 241, 177-181. 